\title{
Gangrena de Fournier: uma emergência urológica que devemos reconhecer - a propósito de um caso clínico
}

Sara Lisa Pinho, ${ }^{1}$ Rafael Henriques, ${ }^{1}$ Natália Guerreiro ${ }^{2}$

\section{RESUMO}

Introdução: Em medicina geral e familiar é frequente a abordagem de quadros clínicos em fase inicial, com semiologia inespecífica. Cabe ao médico de família orientar adequadamente a articulação com os cuidados de saúde secundários, sobretudo nos casos urgentes. A gangrena de Fournier (GF) é uma infeção necrotizante rara, mas potencialmente fatal, cujo diagnóstico e tratamento atempados podem salvar a vida do doente.

Descrição do caso: Homem de 66 anos de idade, recorreu à consulta por dor anal e febre com dois dias de evolução. Dos antecedentes pessoais destaca-se diabetes mellitus tipo 2, hipertensão arterial e dislipidemia. Ao exame objetivo apresentava-se apirético, com bom estado geral e com hemorroida externa não trombosada, sem outras alterações. No dia seguinte recorreu de novo à consulta por manter febre, apresentando também mau estado geral e dor testicular intensa, com oito horas de evolução. Ao exame físico, além de má impressão clínica, objetivou-se edema e rubor acentuados da região escrotal. Optou-se pelo envio ao serviço de urgência hospitalar onde realizou ecografia escrotal que revelou orquite esquerda. Iniciou antibioterapia endovenosa empírica, foi internado no serviço de urologia e no terceiro dia de internamento evoluiu para necrose da região escrotal com extensão perineal. Foi submetido a desbridamento cirúrgico de tecidos necrosados com necessidade de colostomia de derivação e posterior intervenção por parte da cirurgia plástica para reconstrução do defeito escrotal e perianal.

Comentário: A GF é uma infeção urogenital necrotizante grave. Neste doente, a orquite como ponto de partida da infeção e a diabetes como fator predisponente contribuíram para o desenvolvimento da doença. Torna-se clara a importância da articulação entre os cuidados de saúde primários e secundários, pois o diagnóstico em tempo útil e o tratamento adequado neste caso permitiram contrariar a elevada taxa de mortalidade associada a esta patologia.

Palavras-chave: Cuidados de saúde primários; Diabetes; Gangrena de Fournier; Patologia urológica.

\section{INTRODUÇÃO}

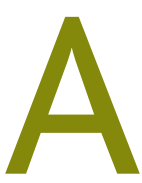
s infeções da pele e dos tecidos moles são uma causa frequente de procura de cuidados médicos e a sua apresentação é muito variável, podendo envolver desde as camadas superficiais até aos músculos e fáscias mais profundas. ${ }^{1}$ Dentro das infeções do foro urológico existem situações graves que devemos reconhecer uma vez que exigem um diagnóstico urgente e referenciação atempada. ${ }^{2} \mathrm{~A}$ gangrena de Fournier (GF) é uma infeção urogenital pouco frequente, mas a sua incidência exata não é co-

1. Médico Interno de Medicina Geral e Familiar. USF BRIOSA. 2. Médica Assistente em Medicina Geral e Familiar. USF BRIOSA. nhecida. ${ }^{3}$ Sabe-se que ocorre sobretudo em indivíduos do sexo masculino entre os 50 e os 70 anos, mas pode atingir ambos os géneros ou qualquer faixa etária..$^{3-4} \mathrm{~A}$ importância de saber reconhecer atempadamente esta doença prende-se com o facto de esta ter um mau prognóstico, com elevada morbimortalidade associada. ${ }^{5}$ Além disso, entre os doentes que sobrevivem, frequentemente persistem sequelas físicas, psicológicas e sociais marcadas.

É sabido que o médico de família lida muitas vezes com sintomatologia inespecífica na fase inicial do quadro clínico, mas deve reconhecer a semiologia da doença e estar atento aos sinais de alarme que devem 
motivar referenciação urgente para os cuidados de saúde secundários.

Com este relato de caso pretende-se sensibilizar o leitor para uma das principais emergências urológicas, a GF, uma doença rara, mas potencialmente fatal.

\section{DESCRIÇÃO DO CASO}

O caso clínico é referente a um homem de 66 anos de idade, caucasiano e comerciante de profissão. É casado, estando inserido numa família nuclear, de classe média segundo a escala de Graffar e no estadio VII do ciclo de vida familiar de Duvall. Dos antecedentes pessoais destaca-se diabetes mellitus tipo dois, hipertensão arterial, dislipidemia e obesidade de classe I (índice de massa corporal de $30,84 \mathrm{~kg} / \mathrm{m}^{2}$ ). A medicação habitual é a seguinte: metformina+vildagliptina $1000+$ $50 \mathrm{mg} 2 i d$, irbesartan+hidroclorotiazida $300+12,5 \mathrm{mg}$ id e atorvastatina $40 \mathrm{mg} i d$. Sem hábitos tabágicos ou alcoólicos conhecidos.

Em março recorreu à consulta do dia por dor anal com semanas de evolução, apesar de estar a aplicar analgésico tópico (pomada de policresuleno e cloridrato de cinchocaína $50+10 \mathrm{mg} / \mathrm{g}$ ). Associadamente, apresentava-se no segundo dia de febre que cedia à toma de paracetamol. Referia noção de congestão nasal e disfonia, sem outras queixas nomeadamente respiratórias, gastrointestinais ou genito-urinárias. Ao exame objetivo apresentava-se apirético e com bom estado geral. A inspeção anal revelou hemorroida externa não trombosada, com toque retal indolor e sem outras alterações. Foram prescritos bioflavonoides em esquema de crise hemorroidária e explicados os sinais de alarme que deveriam motivar nova observação médica, além da indicação para vigiar a temperatura.

No dia seguinte recorreu de novo à consulta por manter febre (pico máximo de $39,2{ }^{\circ} \mathrm{C}$ ), apresentando agora também prostração acentuada e dor testicular exuberante, com cerca de oito horas de evolução. Ao exame físico, apesar da má impressão clínica, apresentava-se hemodinamicamente estável (TA 109/54mmHg e FC 80bpm). Objetivou-se edema e rubor acentuados da região escrotal. Por este motivo, optou-se pelo envio ao serviço de urgência hospitalar onde foi observado pelos colegas de urologia e realizou exames complementares de diagnóstico. Analiticamente apresentava elevação da proteína $\mathrm{C}$ reativa $(46 \mathrm{mg} / \mathrm{dL})$, discre- ta leucocitose $\left(11,8 \times 10^{\wedge} 9 / \mathrm{L}\right)$, alterações eletrolíticas ligeiras ( $\mathrm{Na}+132 \mathrm{mmol} / \mathrm{L}$ e Cl- $96 \mathrm{mmol} / \mathrm{L})$ e hiperglicemia $(211 \mathrm{mg} / \mathrm{dL})$. Revelava ainda algum rebate na função renal (creatinina de 1,42mg/dL e azoto ureico de $38 \mathrm{mg} / \mathrm{dL}$ ). A urocultura foi negativa. A ecografia escrotal revelou testículo esquerdo tumefacto e com textura hipoecogénica, com espessamento das túnicas e do tecido celular subcutâneo associado a exuberante enfisema subcutâneo, tendo sido feito o diagnóstico de orquite esquerda. Posto isto, iniciou antibioterapia endovenosa empírica com ceftriaxona em regime de internamento no serviço de urologia.

Ao terceiro dia de internamento, apesar da antibioterapia de largo espectro instituída, a infeção evoluiu de forma fulminante para fasceíte necrotizante da região escrotal com extensão perineal, tendo sido submetido de imediato a desbridamento cirúrgico de tecidos necrosados. Por proximidade com a área intestinal foi pedida a colaboração da cirurgia geral, que entendeu ser necessária a realização de colostomia de proteção. O exame cultural do tecido desbridado revelou-se positivo para a presença de Enterococcus faecalis.

Em abril, cerca de um mês depois da primeira intervenção cirúrgica de emergência, foi submetido à primeira reconstrução do defeito escrotal e perianal com retalho fasciocutâneo das coxas. Teve alta em maio, cerca de dois meses após o internamento, mantendo cuidados de penso no centro de saúde.

Em setembro do mesmo ano recorreu ao serviço de urgência hospitalar por quadro de mialgias, arrepios e febre com três dias de evolução associado a eritema da coxa direita com agravamento progressivo, indolor e não pruriginoso, com extensão posterior à coxa contralateral. Foi feito o diagnóstico de dermo-hipodermite bacteriana aguda nas áreas de cicatrizes das coxas e foi novamente internado, desta vez no serviço de dermatologia, para administração de antibioterapia endovenosa com cefazolina e clindamicina. Teve alta ao oitavo dia de internamento, com indicação para manter profilaxia com lentocilina intramuscular até completar tratamento de reconstrução da área genital.

Na sequência das várias cirurgias e internamentos sucessivos e prolongados, o doente teve de suspender a sua atividade profissional. A complexidade desta situação obrigou não só a mudanças laborais e profissionais, mas também a uma reorganização da 
dinâmica familiar, uma vez que a esposa assumiu o papel de cuidadora.

Durante a fase de crise, a família constituiu um adequado recurso de suporte, acompanhando o doente às consultas e aos sucessivos tratamentos aos quais foi submetido e garantido ainda o apoio necessário nas atividades do dia a dia, como os cuidados com as áreas desbridadas e com a colostomia. Por outro lado, também o agregado familiar foi influenciado pela doença deste elemento e, no caso da esposa, existiu agravamento da perturbação depressiva e ansiedade com necessidade de ajuste da medicação psicotrópica.

Atualmente o doente apresenta evolução favorável, tendo já sido submetido à reconstrução total da região genital bem como ao encerramento do estoma do intestino com reconstituição do trânsito intestinal. Progressivamente foi retomando a sua autonomia para as atividades de vida diárias, embora tenha suspendido definitivamente a atividade profissional, progredindo assim para a fase VIII do ciclo de vida familiar de $\mathrm{Du}$ vall.

\section{COMENTÁRIO}

A GF é uma fasceíte necrotizante aguda e potencialmente fatal que envolve a pele e os tecidos moles do escroto e do períneo, mas pode estender-se também à parede abdominal inferior e raiz das coxas. ${ }^{7}$

Na sua génese está uma infeção polimicrobiana por microrganismos aeróbios e anaeróbios e cujos agentes patogénicos mais frequentemente encontrados são $E s$ cherichia coli, Streptococcus pyogenes, Staphylococcos aureus, Klebsiella pneumonia, Pseudomonas aeruginosa, Proteus mirabilis, enterococci, Bacteroides fragilis e streptococcus anaeróbicos. Mais raramente pode estar presente o fungo Candida Albicans..$^{2-3,7-8}$ Recentemente tem havido uma crescente incidência de espécies multirresistentes com morbimortalidade aumentada. ${ }^{1}$

Entre os fatores de risco mais conhecidos destacam-se: diabetes, idade avançada, alcoolismo, obesidade, tabagismo, neoplasias e imunossupressão, sendo a primeira a comorbilidade mais frequentemente associada à doença. ${ }^{7}$ Infeções do trato urinário, infeções perianais e traumatismos da região genital poderão funcionar como portas de entrada (Tabela 1). ${ }^{3-4,7}$

Os sinais e sintomas mais comuns incluem febre, dor, edema e rubor na região perianal e genital. Geral- mente estes doentes apresentam-se com dor desproporcionalmente intensa relativamente ao restante exame objetivo. ${ }^{2}$ Em casos mais graves pode observar-se taquicardia e instabilidade hemodinâmica. ${ }^{4}$ Contudo, o diagnóstico inicial é dificultado pela sintomatologia inespecífica e pelo facto de não existirem sinais patognomónicos. ${ }^{1,4}$

O diagnóstico é clínico, mas os achados laboratoriais mais frequentes incluem leucocitose, distúrbios eletrolíticos e elevação dos parâmetros inflamatórios. A tomografia computorizada ou a ressonância magnética podem ser úteis para avaliar a extensão da doença. ${ }^{9}$

O diagnóstico diferencial deve ser feito com as formas gangrenosas de vulvite e balanite em doentes com diabetes concomitante, ulcerações ou cancroide. ${ }^{4}$

A gravidade desta infeção e a necessidade de a saber reconhecer precocemente reside no facto de apresentar uma progressão muito rápida de celulite na região perineal ou perianal para fasceíte necrotizante que pode atingir $\mathrm{o}$ abdómen, flancos e parede torácica, havendo relatos de progressões da área necrosada de dois a três centímetros por hora. ${ }^{2,4}$

Posto isto, facilmente se compreende que o tratamento deve ser imediato e gerido de forma multidisciplinar. Consiste normalmente em intervenção cirúrgica, antibioterapia de largo espectro e suporte hemodinâmico. ${ }^{3,5} \mathrm{Na}$ maioria dos casos são necessárias várias intervenções cirúrgicas nas primeiras 24 a 48 horas após o desbridamento inicial. ${ }^{2}$ Nas semanas seguintes o doente é ainda submetido a vários procedimentos de reconstrução, conforme a extensão da área afetada.

Apesar do tratamento agressivo e da antibioterapia de largo espectro, a taxa de mortalidade é elevada, variando entre 16 a $88 \% .5,7,9$ Pode progredir rapidamente para complicações locais severas ou ainda para doença sistémica como sepsia, coagulopatia, insuficiência renal aguda, cetoacidose diabética e falência multiorgânica. ${ }^{1,3}$ São fatores de mau prognóstico: idade avançada, comorbilidades associadas, atraso no diagnóstico e no tratamento e uma grande extensão da área afetada. ${ }^{?}$

Após a alta hospitalar, estes doentes devem manter cuidados com a ferida cirúrgica, pois o controlo da infeção é fundamental para o sucesso terapêutico. ${ }^{7}$

As cirurgias necessárias para o tratamento da doença e controlo da infeção são muito mutilantes e estão associadas a alterações da imagem corporal, dor 
TABELA 1. Principais causas associadas ao desenvolvimento de Gangrena de Fournier ${ }^{3-4}$

\section{Causas no homem}

\begin{tabular}{l|l}
\hline Anorretais & Abcessos perianais, fissuras anais, hemorroidas, fístula anal, doença inflamatória intestinal, diverticulite \\
\hline Urogenitais & Infeção das glândulas bulbo-uretrais, lesão uretral, epididimite, orquite, infeção do trato urinário inferior \\
\hline Dermatológicas & Hidradenite supurativa, feridas, higiene inadequada \\
\hline Outros & Piercings genitais, instrumentação uretral, injeções intramusculares, implantes penianos \\
\hline
\end{tabular}

Causas na mulher

Abcessos da glândula de Bartholin, episiotomias, histerectomia

\section{Causas na criança}

Circuncisão, picada de inseto, traumatismos, queimaduras

crónica e disfunção sexual, pelo que estes doentes podem apresentar distúrbios emocionais associados que não devem ser negligenciados. ${ }^{3-4}$ Também a dinâmica familiar é afetada, uma vez que um indivíduo anteriormente ativo e independente para as atividades de vida diária passa a necessitar dos cuidados de outro, com necessidade de ajuste dos papéis dentro da família.

O triângulo terapêutico médico-doente-família torna-se, assim, fundamental no sentido de proporcionar a estes utentes os cuidados médicos necessários, mas garantindo ainda o suporte social e emocional capaz de influenciar positivamente este processo de reação e adaptação à doença.

Como principais mensagens a reter deste relato de caso destacam-se:

- Em medicina geral e familiar são frequentes os quadros clínicos em fase inicial e com semiologia inespecífica, pelo que se deve saber reconhecer precocemente os sinais de alarme e garantir sempre a acessibilidade de cuidados;

- Perante uma população com fatores de risco (diabetes, idade avançada, alcoolismo, obesidade, tabagismo, neoplasias ou imunossupressão), sinais de alarme como febre com prostração associada, edema e dor testicular devem motivar sempre a referenciação a um serviço de urgência;

- No doente diabético, além de reconhecer os sinais e sintomas, deve-se promover o bom controlo glicémico; ${ }^{4}$
- A GF trata-se de uma emergência urológica que, apesar da ausência de sinais patognomónicos, é potencialmente fatal e exige um diagnóstico atempado e um tratamento rápido e agressivo;

- A abordagem deve ser multidisciplinar, assente numa boa articulação entre os cuidados de saúde primários e secundários.

O papel do médico de família na construção de uma relação de proximidade e de continuidade, não só com o doente, mas também com a sua família, constitui um aspeto essencial na adaptação à doença e no processo de reabilitação.

\section{REFERÊNCIAS BIBLIOGRÁFICAS}

1. Raya-Cruz M, Payeras-Cifre A, Ventayol-Aguiló L, Díaz-Antolín P. Factors associated with readmission and mortality in adult patients with skin and soft tissue infections. Int J Dermatol. 2019;58(8):916-24.

2. Palka J. 12 Urologic emergencies you need to know. Medscape.com [homepage]; 2018 [updated 2019 Feb 12]. Available from: https://reference.medscape.com/slideshow/urologic-emergencies-6008708\#1

3. Pais Jr VM, Santora TA, Rukstalis DB, Sollender GE. Fournier gangrene. Medscape.com [homepage]; 2018 [updated 2019 May 7]. Available from: https://emedicine.medscape.com/article/2028899-overview

4. Gadler T, Huey S, Hunt K. Recognizing Fournier's gangrene in the emergency department. Adv Emerg Nurs J. 2019;41(1):33-8.

5. Kranz J, Schlager D, Anheuser P, Mühlstädt S, Brücher B, Frank T, et al. Desperate need for better management of Fournier's gangrene. Cent European J Urol. 2018;71(3):360-5.

6. Lin TY, Cheng $\mathrm{HH}, \mathrm{Ou} \mathrm{CH}$, Tsai YS, Tong YC, Cheng HL, et al. Incorporating Simplified Fournier's Gangrene Severity Index with early surgical intervention can maximize survival in high-risk Fournier's gangrene patients. Int J Urol. 2019;26(7):737-43. 
7. Hahn HM, Jeong KS, Park DH, Park MC, Lee IJ. Analysis of prognostic factors affecting poor outcomes in 41 cases of Fournier gangrene. Ann Surg Treat Res. 2018;95(6):324-32.

8. Efem SE. The features and aetiology of Fournier's gangrene. Postgrad Med J. 1994;70(826):568-71.

9. Onder CE, Gursoy K, Kuskonmaz SM, Kocer U, Culha C. Fournier's gangrene in a patient on dapagliflozin treatment for type 2 diabetes. J Diabetes. 2019;11(5):348-50

\section{CONFLITO DE INTERESSES}

Os autores declaram não ter quaisquer conflitos de interesse.

\section{FINANCIAMENTO DO ESTUDO}

O trabalho relatado neste manuscrito não foi objeto de qualquer tipo de financiamento externo (incluindo bolsas de investigação).

\author{
ENDEREÇO PARA CORRESPONDÊNCIA \\ Sara Lisa Pinho \\ E-mail: sarabanaco@hotmail.com \\ https://orcid.org/0000-0001-6234-013X
}

Recebido em 08-06-2019

Aceite para publicação em 01-03-2020

\section{ABSTRACT}

\section{FOURNIER GANGRENE: A UROLOGIC EMERGENCY THAT WE MUST RECOGNIZE - A CASE REPORT}

Introduction: It is common for the family physician (FP) to approach cases in their initial phase, with nonspecific semiology. Part of his functions is to properly manage the articulation with the secondary health care, especially emergencies. Fournier's gangrene (FG) is a rare but potentially fatal necrotizing infection, whose timely diagnosis and treatment may save the patient's life.

Case description: A 66-year-old male reached his FP due to anal pain and fever for two days. From his medical history, we highlight type two diabetes, hypertension, and dyslipidaemia. He presented with no fever or acute distress, and his rectal exam only revealed non-thrombosed haemorrhoid. He returned on the next day to an emergency appointment due to maintaining his previous symptoms plus a worse general status and intense testicular pain with an eight hours evolution. Physical exam revealed, besides a bad clinical impression, oedema, and flushing of the scrotal region. He was immediately directed to the hospital's emergency room, where it was performed a scrotal ultrasound that revealed left orchitis. The patient started empiric intravenous antibiotics and was admitted to the urology department. On the third day of hospitalization, he developed scrotal necrosis with perineal extension and was submitted to surgical debridement of the necrotized tissues, with the need for a derivative colostomy and posterior intervention by plastic surgery for reconstruction of the scrotal and perianal regions. Currently, he shows a favourable evolution.

Comment: FG is a serious necrotizing urogenital infection. On this patient, haemorrhoid as a site of entry and diabetes as a predisposing factor might have contributed to the development of the disease. It emphasizes the importance of proper articulation between primary and secondary health care because of early diagnosis and treatment in this case allowed to beat the odds of the high mortality associated with this disease.

Keywords: Primary health care; Diabetes; Fournier gangrene; Urologic diseases. 